\title{
DISPOSITIVOS LÚDICOS PARA EL ARTE
}

\section{PLAYFUL DEVICES FOR ART}

MIGUEL ÁNGEL LEDEZMA CAMPOS

Universidad Autónoma del Estado de Hidalgo, México

http://orcid.org/oooo-0002-2211-2244

miguel_ledezma4913@uaeh.edu.mx
Recepción: 12 de julio de 2021

Aprobación: 21 de septiembre de 2021
RESUMEN

Este artículo tiene por objetivo analizar las relaciones entre arte y juego desde la teoría y desde la producción artística. En primer lugar, se explica el desarrollo de una herramienta metodológica que clasifica las diversas relaciones lúdicas entre el artista, la obra y el espectador, así como su articulación con los cuatro tipos de juego planteados por Roger Caillois. Después, se revisa el significado del concepto dispositivo en las filosofías de Jacques Rancière y de Michel Foucault, posteriormente, se explica el término dispositivos lúdicos para el arte. Finalmente, se presenta un proyecto artístico personal como producto de la metodología.

Palabras clave: arte contemporáneo, juego, dispositivos de visibilidad, arte participativo

\section{ABSTRACT}

This article aims to analyze the relationships between art and play from theory and from artistic production. To do this, a methodological tool was developed that classifies the various playful relationships between the artist, the work and the viewer, as well as their articulation with the four types of game proposed by Roger Caillois. Also, the meaning of the device concept in the philosophies of Jacques Rancière and Michel Foucault will be analyzed, for the construction of the term ludic devices. Finally, a personal artistic project will be presented as a product of the methodology of this research project.

Keywords: contemporary art, play, visibility devices, participatory art 
Los juegos tienen una incidencia crucial en todas las culturas. Desde el enfoque de algunos autores, como Johan Huizinga (2000), Roger Caillois (1986) y Hans Georg Gadamer (1991), el arte también guarda estrechas relaciones con el juego, de hecho, es posible afirmar que el arte es juego. Sin embargo, es necesario matizar esta afirmación, ya que, si el arte es juego, luego entonces, ¿quién juega en el arte: el autor, el espectador o ambos?, si es así, ¿cómo se juega en el arte?

La presente investigación tiene como objetivo general, vincular los aportes más significativos de las teorías del juego elaboradas por Huizinga, Caillois y Gadamer con las prácticas artísticas del arte actual para comprender las características principales de los dispositivos lúdicos en el arte, principalmente, a través de la tipología del juego elaborada por Caillois, originalmente en 1958. Además, destaca entre los objetivos particulares, la aplicación de los conocimientos generados en la investigación para la producción artística personal.

El presente artículo es la sección final de una amplia investigación individual elaborada en torno a las relaciones entre el juego y el arte contemporáneo, y complementa una publicación anterior en donde se analizaron algunos casos de estudio para comprender el arte como competencia, azar, simulacro y vértigo (Ledezma-Campos, 2019), es decir, la tipología de los juegos planteada por Roger Caillois (1986). En este artículo también se presentará la aplicación práctica de esta investigación, a través de un proyecto artístico personal que lleva por nombre Casa escultura, elaborado en Hidalgo, México, entre 2012 y 2014.

Según Huizinga (2000), el juego es generador de cultura en la sociedad. En su texto Homo ludens, le otorgó un papel central a la competencia o agón y argumentó que, aunque de manera sutil, el juego sigue presente en varias actividades sociales, tales como la filosofía, el derecho, la poesía e incluso la guerra.

Por otra parte, Roger Caillois (1986), a inicios de la primera mitad del siglo XX, retomó los estudios iniciales de Huizinga, pero desde un enfoque crítico, ya que señaló que existen otros juegos, además de los juegos de competencia, en los cuales se centró únicamente Huizinga (2000) en el texto antes mencionado. Uno de los aportes principales de Roger Caillois es la elaboración de una tipología de los juegos, en donde afirma que existen cuatro tipos: los juegos de agón o competencia, los juegos de alea o azar, los juegos de mimicry o simulacro, y los juegos de ilinx o vértigo.

Paralelamente a la publicación del texto de Roger Caillois (1986), intitulado Los juegos y los hombres, el filósofo alemán Hans Georg-Gadamer publicó su obra más reconocida: Verdad y método en el año 1960 en donde abordó por primera vez las relaciones entre el arte y el juego. Para Gadamer toda experiencia estética es un juego, ya que es una actividad libre y desinteresada que implica una actividad hermenéutica de coparticipación, la cual es inherente a todo tipo de juego. Los trabajos de estos tres autores, Huizinga, Caillois y 
MIGUEL ÁNGEL LEDEZMA CAMPOS Dispositivos lúdicos para el arte
Gadamer, son referentes básicos para la comprensión de la importancia que tiene el juego en la cultura y en el arte.

Huizinga (2000), señaló que en algunos idiomas la relación entre el juego y el arte se encuentra planteada desde el lenguaje, ya que la palabra play, del idioma inglés, se traduce como juego, pero también se aplica cuando una persona ejecuta una melodía en algún instrumento, como lo indica la frase en inglés: He is playing the guitar. También encontró otras coincidencias entre arte y juego, tales como el uso del ritmo y la armonía, agregando que el arte y el juego son actividades que tienden a la colectividad, que hacen comunidad.

Desde un enfoque metodológico, para esta investigación, se abordaron los objetivos de esta investigación desde un enfoque hermenéutico. Los pasos que guiaron el presente proyecto fueron los siguientes:

- búsqueda y selección de fuentes para la elaboración de un archivo bibliográfico, hemerógráfico, videográfico y de obras de arte vinculadas con el juego;

- lectura, interpretación y comprensión del archivo antes mencionado y;

- aplicación de los conocimientos obtenidos en la elaboración de textos, artículos y obras de arte lúdicas.

A continuación se planteará una propuesta tipológica de las relaciones entre arte y juego; posteriormente serán analizadas las relaciones actuales entre arte, juego y sociedad; después, se explicará el significado del término "dispositivo" en las filosofías de Jacques Rancière y de Michel Foucault, posteriormente se enlazará este concepto con el juego y; finalmente, se analizará una de las obras elaboradas por el autor del este artículo, centradas en el tercer paso metodológico del proyecto, que es la aplicación.

\section{TIPOS DE RELACIONES ENTRE ARTE Y JUEGO}

Las variables que existen en las relaciones entre el arte y el juego se volvieron más complejas a partir de las vanguardias del arte moderno a inicios del siglo XX, particularmente, en el Dadaísmo y en el Surrealismo. Los modos de ser de la obra de arte se diversificaron a partir de diversas prácticas, algunas de ellas a través de la utilización del azar. De acuerdo a lo anterior, en la primera parte de esta investigación, se propuso una tipología que sirve como herramienta metodológica para la comprensión de las obras de arte vinculadas con el juego (Ledezma-Campos, 2019).

Respondiendo a la pregunta: ¿quién juega en las obras de arte?, se observaron cuatro tipos, los cuales son:

- la contemplación como juego;

- el artista juega; 
ARTíCULO

MIGUEL ÁNGEL LEDEZMA CAMPOS

Dispositivos lúdicos para el arte
- el público juega — refiriéndonos a una actividad no contemplativa-y;

- artista y público juegan entre sí.

Cabe señalar que la categoría 1, se sustenta en la estética de Gadamer, en donde se plantea la contemplación como una actividad hermenéutica de co-participación entre el autor, la obra y el espectador que pone en juego, no sólo la emoción, sino la imaginación y el entendimiento (Gadamer, 1991).

Para responder a la pregunta: ¿cómo se juega en el arte?, es posible recurrir a los cuatro tipos de juego planteados por Caillois, resultando que existen obras de arte como competencia, como azar, como simulacro y como vértigo (Ledezma-Campos, 2019).

Es posible desarrollar una malla a partir del cruce de ambas tipologías, lo que nos permitirá ubicar, a manera de coordenadas, las diversas obras de arte. Así, por poner un ejemplo, en los diversos toboganes escultóricos que Carsten Höller ha emplazado en diversos museos, es prevalente el juego del público, pero no así del autor, y el tipo de juego en el que se ubica la obra es en los juegos de vértigo. Finalmente, cabe señalar, que ambas tipologías son flexibles, y que una obra puede ser ubicada en varias tipologías a la vez.

Una vez aclarados los antecedentes y las herramientas metodológicas, se abordará a continuación el concepto central del presente texto, los dispositivos lúdicos y su relación con la sociedad que los produce.

\section{ARTE, JUEGO Y SOCIEDAD}

Roger Caillois propone que podemos comprender a las sociedades de acuerdo a los tipos predilectos de juego que éstas practican, ya que estos manifiestan no sólo sus gustos sino sus hábitos y sus modos de razonar (Caillois, 1986). También afirma que existe un antagonismo entre dos tipos de sociedades: las primeras son llamadas "sociedades de confusión" - también conocidas como sociedades primitivas-, en las que prevalecen los juegos de simulacro y de vértigo, a través de rituales en donde el trance y la máscara son los medios para que se produzca una transformación con fines generalmente religiosos. Por otra parte, tenemos las "sociedades de contabilidad" en donde los juegos preferidos son la competencia y el alea azar, son sociedades más ordenadas y calculadoras (Caillois, 1986).

Esto conlleva a preguntar en qué tipo de sociedad vivimos actualmente, y si existe aún ese antagonismo entre las sociedades de confusión y las sociedades calculadoras. A simple vista, en lo que se refiere a los avances tecnológicos y los medios de comunicación, así como el poder que ejercen las empresas transnacionales sobre los estados-nación (Hard, 2000), llevarían a la conclusión de que vivimos en un tipo de sociedad de contabilidad, es decir, una sociedad de control que tiene preferencia por los juegos bien estructurados y con reglas precisas. En efecto, juegos de competencia como el fútbol o las olimpiadas son transmitidos masivamente a lo largo del mundo. Por unos días todos los medios de 
ARTíCULO

MIGUEL ÁNGEL LEDEZMA CAMPOS Dispositivos lúdicos para el arte información centran su atención en estas competencias mundiales, dejando en segundo plano todo tipo de noticias económicas, políticas y culturales. También cabe señalar que la democracia, funciona a través de la estructura de un juego de competencia.

A pesar de que existe una mayor difusión de los juegos reglamentados, lo que interesa subrayar aquí, es que las sociedades contemporáneas no están polarizadas entre una sociedad de confusión o una sociedad de contabilidad, de hecho, es recomendable hacer un análisis más sutil que preste atención no sólo a los juegos preferidos o populares sino al resto de juegos practicados en nuestra sociedad.

Tal parece que, si los juegos de competencia entre adultos son los que tienen más aceptación popular, esto no significa que sean los que más influyen en la sociedad y en la formación de la cultura, ya que según Caillois (1986:140) “los juegos crean hábitos, provocan reflejos. Hacen esperar cierto tipo de reacciones y por consiguiente invitan a considerar las reacciones opuestas como brutales o hipócritas, como provocadores o como desleales".

A finales del siglo XX, Jean Duvignaud (1982) publicó un texto que dio seguimiento al análisis de la relación entre juego y sociedad, previamente desarrollado por Johan Huizinga (2000) y por Roger Caillois (1986). Duvignaud reconoció el gran valor de los estudios anteriores, pero prefirió centrar su estudio, no en la reglamentación, sino en la noción de juego como finalidad sin fin, es decir, más cercana al concepto de paidea, palabra griega que asignaban los griegos al juego de los niños y de los animales. Haciendo una crítica a la correspondencia entre juego y juguete, el autor francés señaló que existe una relación de dominación entre el niño y el adulto a través del juguete, el cual es al mismo tiempo un regalo:

El enunciado negativo -el juguete no es el juego- debería enseñarnos a enfrentar la actividad [lúdica]: el juguete es un don y, por ende, quien lo recibe sin poder corresponder a él, el don implica un reconocimiento o, cuando menos, una sumisión pasajera. Que los objetos [lúdicos] sean producidos por una economía de mercado, que entren dentro del sistema de consumo no cambia nada la intención disfrazada que implica el regalo: la dominación del niño por el adulto (Duvignaud, 1982: 46).

Pero en la relación lúdica del niño con el juguete existe, al mismo tiempo, un acto de resistencia a través de una manipulación destructiva que devuelve la libertad al juego y al juguete, una nueva aplicación para la que no había sido diseñado: "destruyéndolos, los aparta de su función -la grúa se hace auto, el tren proyectil-y los restituye a la indeterminación de las cosas inútiles" (Duvignaud, 1982: 47). En este sentido, es posible hacer una analogía entre el niño que destruye el juguete y el artista que deconstruye el juego. Cuando un artista trabaja desde las estrategias del juego, generalmente subvierte el orden de las convenciones sociales y su trabajo se parece a ese niño que usa y transforma el juguete para sus propias necesidades, llegando incluso a la destrucción o cancelación del juego. 
ARTí́CULO

MIGUEL ÁNGEL LEDEZMA CAMPOS Dispositivos lúdicos para el arte
De acuerdo a lo anterior, parece apremiante prestar atención a los juegos que practican los niños y los adolescentes tanto como el análisis de los juegos de competencia que son difundidos masivamente. ¿A qué juegan los niños actualmente?, ¿qué tipo de libertad proveen estos juegos y juguetes a los niños que los usan?, ¿cuál es el discurso oculto por detrás de estos juegos cotidianos en la infancia?, ¿qué significan los juguetes que los adultos ofrecen a los pequeños?, ¿cómo sería posible subvertir estos juegos y juguetes? Para responder a este conjunto de preguntas se propone la construcción del concepto “dispositivos lúdicos", el cual será explicado con detalle a continuación.

\section{DISPOSITIVOS}

Real Pictures es proyecto muy conocido del artista chileno Alfredo Jaar, el cual articula imágenes y palabras a partir del genocidio de Ruanda en 1994, cuando el gobierno de ese país trató de exterminar a la etnia tutsi mediante masacres que se llevaron a cabo sistemáticamente hasta asesinar prácticamente al $80 \%$ de la población tutsi que vivía en Ruanda.

Ante el creciente número de muertes la prensa del resto del mundo mostró indiferencia y hermetismo, publicando eventualmente sólo pequeñas notas. Acerca de la instalación Real Pictures, Jacques Rancière (2010: 97) comentó que el "problema no es oponer las palabras a las imágenes visibles. Es trastornar la lógica dominante que hace de lo visual la parte de las multitudes y de lo verbal el privilegio de unos pocos".

En cuanto Alfredo Jaar se enteró del conflicto en Ruanda, viajó a ese país para documentar el genocidio. La obra a la que se refiere Rancière está conformada por un conjunto de cajas negras, las cuales contienen en su interior la fotografía de uno o varios tutsis masacrados. Por su exterior, en letras blancas, se puede leer un texto que describe la situación en la que fue tomada la imagen por Alfredo Jaar. Cada caja representa a una víctima con la que se encontró el artista. En su conjunto, dentro de la galería, éstas fueron ordenadas en hileras o en torres formando bloques escultóricos negros que, a su vez, formaban un mosaico de textos narrativos describiendo la masacre.

Las fotografías nunca han sido vistas por el espectador, lo cual no excluye la presencia de las imágenes en esta obra, ya que las palabras que describen la masacre desencadenan imágenes mentales en nuestra imaginación. A este tipo de relación entre imágenes materiales e imágenes inmateriales es a lo que Jacques Rancière (2010: 102-103) llama dispositivos de visibilidad:

Un dispositivo espacio-temporal en el seno del cual son reunidas palabras y formas visibles como datos comunes, como maneras comunes de percibir, de ser afectado y de dar sentido. El problema no es oponer la realidad a sus apariencias. Es construir otras realidades, otras formas de sentido común, es decir, otros dispositivos espacio-temporales, otras comunidades de las palabras y las cosas, de las formas y de las significaciones. [...] Las imágenes del arte no proporcionan armas 
ARTí́CULO

MIGUEL ÁNGEL LEDEZMA CAMPOS Dispositivos lúdicos para el arte para el combate. Ellas contribuyen a diseñar configuraciones nuevas de lo visible, de lo decible y de lo pensable, $y$, por eso mismo, un paisaje nuevo de lo posible.

Los dispositivos de visibilidad descritos por Jacques Rancière evocan a los dispositivos o mecanismos de control sobre el ver y el decir en la filosofía de Michel Foucault, al modelo del panóptico y a la tecnología política del cuerpo, salvo que, en un sentido inverso, positivo. Gilles Deleuze (1987: 51), dice que Foucault muestra que el poder no es

[...] tanto una propiedad como una estrategia, y sus efectos no son atribuibles a una apropiación, 'sino a disposiciones, maniobras, tácticas, técnicas, funcionamientos'; 'se ejerce más que se posee, no es el privilegio adquirido o conservado de la clase dominante, sino el efecto de conjunto de sus posiciones estratégicas'.

En este sentido, se considera que es viable la conformación de obras de arte como dispositivos que combinan estratégicamente palabras e imágenes.

Como es sabido, Foucault (2002), describió un modelo paradigmático de dispositivo de visibilidad elaborado por el inglés Jeremy Bentham en el siglo XVIII, un nuevo modelo arquitectónico de prisión al cual llamó panóptico y cuya forma es la siguiente: un edificio de planta circular en forma de anillo en cuyo centro existe un patio y a su vez una torre de vigilancia. En la sección del anillo se encuentran las celdas, cada una con una ventana hacia el exterior que le brinda iluminación y otra ventana que da hacia la torre:

Basta entonces situar un vigilante en la torre central y encerrar en cada celda a un loco, un enfermo, un condenado, un obrero o un escolar. Por el efecto de la contraluz, se pueden percibir desde la torre, recortándose perfectamente sobre la luz, las pequeñas siluetas cautivas en la celda de la periferia (Foucault, 2002: 204).

Este tipo de dispositivo arquitectónico representa una nueva tecnología que permite el control y vigilancia de varios sujetos por un número reducido de personas. El panóptico funciona tanto física como psicológicamente ya que genera en los prisioneros una sensación permanente de estar siendo vigilado. El individuo se sabe observado, pero no puede ver quiénes lo observan o cuándo está siendo observado. Los avances tecnológicos más recientes han permitido que el panoptismo se extienda a todo tipo de espacios públicos y privados gracias a la implementación de videocámaras, así, un vigilante puede estar al tanto de todo lo que sucede en un edificio sin necesidad de hacer una ronda, ya que un muro de monitores le facilita el trabajo.

La invención del panóptico es resultado de una sofisticación de lo que Foucault (2002) llama "tecnología política del cuerpo" y es un modelo opuesto al calabozo, el cual tenía por principio: "encerrar, privar de luz y ocultar". Ambos modelos encierran al sujeto, pero el 
ARTíCULO

MIGUEL ÁNGEL LEDEZMA CAMPOS Dispositivos lúdicos para el arte primero funciona gracias a la visibilidad y el segundo a la invisibilidad, existe un juego entre ver y no ver, entre observador y observado. A su vez, el castigo del prisionero también es el resultado de un juego entre el decir y el no decir, entre la confesión y la resistencia a confesar. El ver y el decir se amalgaman en un dispositivo, gracias al cual el poder ejerce control sobre los individuos.

El calabozo pertenece a otro tipo de dispositivo de visibilidad, corresponde al periodo de la exhibición pública del castigo y la tortura. Para Foucault (2002: 47), la tortura es un juego, una práctica que se lleva a cabo siguiendo reglas y procedimientos precisos en donde el sospechoso resiste y triunfa o confiesa y pierde:

Sométese al "paciente" - tal es el término por el cual se designa al supliciado- a una serie de pruebas, graduadas en severidad y de las cuales triunfa "resistiendo", o ante las cuales fracasa confesando. Pero el juez no impone la tortura sin aceptar, por su parte, riesgos [...]; arriesga en la partida una baza, a saber, los elementos de prueba que ha reunido ya; porque la regla impone que, si el acusado "resiste" y no confiesa, se vea el magistrado obligado a abandonar los cargos. El supliciado ha ganado.

Desde este enfoque, el dispositivo también es lúdico porque se basa en una lucha dentro de un sistema de reglas precisas. De lo anterior, es posible inferir que algunas obras de arte contemporáneo no sólo son dispositivos de visibilidad sino también dispositivos lúdicos.

Si se relacionan los dispositivos con la teoría del juego de Roger Caillois es posible dividir estos dispositivos en: reglamentados - de competencia y/o azar-, y no reglamentados -de simulacro y/o vértigo-. Un ejemplo representativo de dispositivo lúdico y artístico reglamentado en el arte es la obra Efecto dominó de Gustavo Artigas, en donde el artista creó un sistema de reglas para un concurso de dominó entre cuatro artistas y cuatro prostitutas cubanas en un espacio público de Holguín, Cuba en el año 2000. De acuerdo a dichas reglas, no se le permitió jugar a los voluntarios que se ofrecieron para integrarse al juego, ya que el dispositivo del autor no lo permitió (Artigas, 2013).

En contraste, la obra Test site de Carsten Höller emplazada en la sala de Turbinas de la Tate Modern en el año 2006, es un dispositivo lúdico no reglamentado, ya que no existía reglamentación alguna para que los usuarios se pudiesen desplazar vertiginosamente a través del espacio de la galería mediante un dispositivo de cinco enormes toboganes distribuidos a lo largo de todo el edificio. Lo importante de este tipo de dispositivos es que el lenguaje del arte acontece jugando. La experiencia lúdica es, al mismo tiempo, una experiencia estética que produce significados. En el caso particular de Test site los toboganes hacen una crítica a la solemnidad de la arquitectura institucional, haciendo la propuesta de la implementación de toboganes en edificios públicos, los cuales son más efectivos para el desplazamiento, además de ser divertidos. Al mismo tiempo, postulan 
ARTíCULO

MIGUEL ÁNGEL LEDEZMA CAMPOS

Dispositivos lúdicos para el arte a la escultura como un nuevo tipo de objetos que van más allá de la contemplación para su uso interactivo y lúdico.

\section{APLICACIÓN: FRACCIONAMIENTO FLAMINGOS DEL PROYECTO CASA/ESCULTURA}

La aplicación es una actividad central que surge de los objetivos de este artículo, así como del planteamiento metodológico mencionado. Los engranajes que articulan la relación entre la teoría y la práctica permiten el funcionamiento de toda investigación en artes. A continuación, se presentarán brevemente los resultados prácticos de la investigación sobre arte y juego desde el desarrollo de una propuesta artística personal.

En el proyecto Casa/escultura que inició en el año 2012, las obras producidas giran en torno a las relaciones entre la distribución geográfica y social de las viviendas. También exploran los posibles vínculos formales entre los reducidos complejos arquitectónicos de interés social y las formas básicas de la escultura minimalista. De acuerdo al cruce de tipologías, estas obras también pueden ser localizadas dentro de las categorías lúdicas de competencia, azar, simulacro y vértigo, así como en las categorías de las relaciones entre artista-obra-espectador, las cuales fueron descritas en la introducción de este artículo.

En las últimas décadas, la zona metropolitana de la Ciudad de México se desbordó hasta fusionarse con el Estado de México mediante la construcción desmedida y no planificada de unidades de casas unifamiliares para trabajadores con bajos recursos. A las orillas del Estado de México los municipios colindantes con la Ciudad de México se han convertido en ciudades dormitorio. Los habitantes de estas unidades habitacionales generalmente trabajan en la ciudad por lo que deben pasar horas en el transporte urbano diariamente.

La suma de las horas de desplazamiento entre el trabajo y el hogar más las horas del horario laboral dan como resultado que muchos trabajadores utilicen sus hogares únicamente para dormir y asearse. Aunado a lo anterior, la adquisición de estas casas o departamentos se hace a través de créditos hipotecarios, lo cual compromete al propietario a seguir siendo asalariado para poder solventar su deuda lentamente. Para estos ciudadanos el tiempo de ocio se ve reducido considerablemente y el supuesto bienestar de poseer una vivienda propia se suma al resto de las estrategias que hacen del individuo un cuerpo dócil que se somete a las relaciones de trabajo y biopolítica.

Formalmente, estos fraccionamientos son construidos mediante la repetición masiva de un mismo modelo arquitectónico: una casa es igual a la que está al lado y, a su vez, es igual a la que está a cinco o seis calles. Dependiendo del costo y la ubicación geográfica estas construcciones son más o menos estrechas, sometiendo a sus habitantes a vivir en condiciones de espacio miserables.

Algunas obras del proyecto Casa/escultura están conformadas por módulos escultóricos habitables - con la imagen de una casa de interés social o de un edificio multifamiliar por su exterior-. La forma y función de cada pieza está determinada de acuerdo al lugar en 
ARTí́CULO

MIGUEL ÁNGEL LEDEZMA CAMPOS Dispositivos lúdicos para el arte

Imagen 1. Fraccionamiento Flamingos. Miguel Ledezma (2012). donde son emplazados esos módulos. Generalmente las obras del proyecto pertenecen a la categoría lúdica de simulacro o mimicry, como los juegos que utilizan juguetes que son réplicas miniatura de objetos cotidianos en el mundo de los adultos, tales como autos, armas, cocinetas, entre otros. En algunas obras del proyecto, además de ser contempladas por el espectador, éste también puede jugar o interactuar con ellas lúdicamente. Por cuestiones de espacio describiremos únicamente la obra Fraccionamiento Flamingos del año 2012 [ver Imagen 1].

Sobre la carretera que une a la Ciudad de México con Pachuca se han construido, y se siguen construyendo, enormes complejos habitacionales. Si uno viaja saliendo de la Ciudad de México, al atravesar la única caseta de esa autopista se pueden observar enormes bloques de casas idénticas que rodean la carretera por ambos lados en Tecámac, Estado de México. Más adelante termina el Estado de México e inicia Hidalgo, atravesando el municipio de Tizayuca. Aquí se ubican un par de balnearios sobre la autopista en dirección a Pachuca, el más vistoso de ellos lleva por nombre "Flamingos" y se encuentra a mitad del camino entre ambas ciudades.

Justo frente al balneario, del otro lado de la carretera, en el momento en que se construyó la obra, en 2012, estaban a la venta las casas del fraccionamiento "Villa de los milagros". A la entrada se podía leer que se ofertaban propiedades con la "mayor plusvalía". Sin

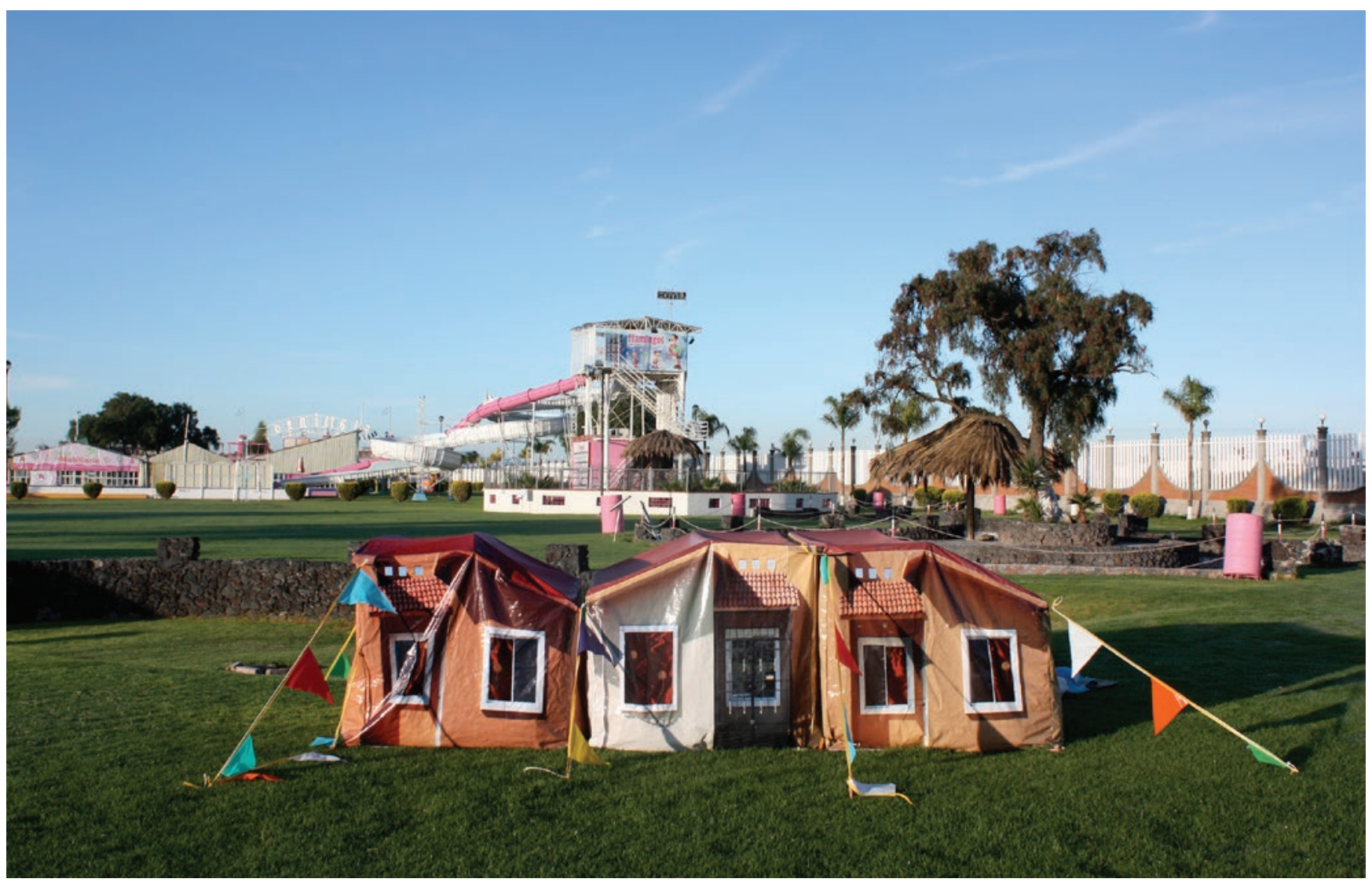


ARTíCULO

MIGUEL ÁNGEL LEDEZMA CAMPOS Dispositivos lúdicos para el arte embargo, el entorno de las casas de "Villa de los milagros" es desolado, no hay fraccionamientos vecinos, mucho menos tiendas u otro tipo de comercios. Para quien se desplaza sin vehículo, habitar aquí puede ser bastante hostil.

Observando el entorno, se puede inferir que la constructora oferta esas casas más para el descanso, que para habitarlas cotidianamente. De acuerdo a lo anterior, la obra Fraccionamiento Flamingos, tenía como objetivo hacer un complejo habitacional más cerca del balneario, inclusive dentro de él.

En el proyecto Casa/escultura se pone en juego la escala aberrante (Lafferty, 2005), que es una estrategia que combina el hiperrealismo y la representación a escala. Fraccionamiento Flamingos está compuesta por tres tiendas de campaña, hechas con lona, impresas por todas sus caras. Cada una mide 120 centímetros de alto por 120 de ancho y 200 centímetros de profundidad. Estas medidas son similares a una tienda de campaña para dos personas. Como imagen representan una casa de interés social de un solo nivel y en conjunto simulan ser un bloque de tres casas a escala, perfectamente habitables, con una puerta por el frente y una ventana por la parte posterior.

Los días 1 y 2 de septiembre de 2012 los módulos escultóricos fueron emplazados en la zona de campamento del Balneario Flamingos y habitados por la familia del autor y otra familia invitada.

¿Cuál es el papel que desempeña el juego en esta obra como dispositivo? Entre los juguetes que hacen referencia a la casa y al hogar se tienen los castillos y casas miniatura que son ubicados generalmente en los patios y jardines dentro del espacio doméstico, los cuales permiten a niños, de entre 2 y 7 años, imitar las actividades que hacen sus padres. Estos juguetes forjan en el niño la noción de que tener una casa propia es una necesidad vital, a pesar de que cuando sea adulto esta adquisición lo encadene a una vida sedentaria, que probablemente lo limitaría a traslados que van de su casa al trabajo y viceversa, ya que, generalmente, una persona de clase media o baja, al adquirir una propiedad también adquiere una deuda que liquidará entre 10 y 25 años.

En la obra Fraccionamiento Flamingos, siguiendo la estrategia de los juegos de imitación o mimicry, se reprodujeron casas de interés en miniatura, el juguete no aumentó en escala, sólo se volvió más realista gracias al uso de la fotografía. El simulacro no estaba únicamente centrado en las tiendas de campaña sino en el balneario en su totalidad que las contenía, un paraíso artificial para las familias del centro del país que no cuentan con recursos suficientes para viajar a la playa. Así, esta obra funciona como una sátira sobre el problema de la vivienda, así como de las tensiones generadas entre la elección de tener una vida nómada o sedentaria.

Las personas que habitamos este pequeño fraccionamiento en la zona de acampar del balneario, jugamos a habitar una casa soñada, con grandes jardines y albercas. Al mismo tiempo, se puso en juego la tensión entre el mueble y el inmueble, ya que nuestras casas podrían recorrerse más cerca o más lejos de la alberca. Además, estas casas/escultura 
ARTíCULO

MIGUEL ÁNGEL LEDEZMA CAMPOS Dispositivos lúdicos para el arte como módulos habitables, tienen la posibilidad de ser montadas en cualquier lugar, lo cual plantea la posibilidad de tener un hogar desplazable y una vida nómada.

De acuerdo a la tipología de las relaciones lúdicas entre el artista, la obra y el espectador, Fraccionamiento Flamingos es una pieza en donde el autor y otras personas juegan al mismo tiempo. Además, esas reproducciones arquitectónicas a escala se prestan a la contemplación del público. Durante su emplazamiento, algunos visitantes al balneario se detuvieron algunos momentos para observar y posteriormente continuar con sus actividades de esparcimiento.

La presente obra, agrega una cualidad más: la especificidad de sitio, ya que, para el proyecto, las instalaciones del balneario e incluso el fraccionamiento "Villa de los milagros", que está enfrente, eran significativos, como si el crecimiento urbano se hubiese desbordado hasta introducirse en el balneario, por lo que se concluye que el Fraccionamiento Flamingos es un dispositivo lúdico de especificidad de sitio.

Los proyectos de especificidad de sitio, tienen como antecedente la historia de la escultura y su relación con los monumentos, es decir, esculturas emplazadas en un lugar particular para conmemorar algo. Posteriormente, en el periodo del arte moderno, la mayoría de las esculturas se volvieron independientes del lugar en donde son presentadas, como la obra de Brancusi. Finalmente, algunos artistas de la segunda mitad del siglo XX, como Richard Serra, retomaron el interés por hacer obras para un lugar específico, reestableciendo las relaciones entre el paisaje, la arquitectura y la escultura. Este tipo de obras se ubicaban en un juego de tensiones entre la escultura, la arquitectura y el paisaje, es decir, un campo expandido (Krauss, 2006). De acuerdo a lo anterior, Fraccionamiento Flamingos puede ser ubicado dentro del eje complejo del campo ya que desarrolló articulaciones entre la escultura, el paisaje y la arquitectura desde el simulacro y el juego. En esta obra el espectador y el autor se tornan jugadores gracias a la estructura del dispositivo de juego.'

\section{CONCLUSIONES}

A partir de lo expuesto en este artículo, se concluye que la experiencia del arte es estética, y, además, lúdica. Para activar los diversos tipos de juego en el arte, tales como los juegos de azar, de simulacro, de vértigo o de competencia, generalmente los artistas elaboran dispositivos lúdicos. Estos dispositivos están vinculados con los dispositivos de visibilidad descritos por Michel Foucault y por Jacques Rancière, en donde se ponen juego las relaciones entre mirar y ser visto, entre mostrar y decir, entre las imágenes y las palabras.

Los dispositivos lúdicos son plataformas donde, a través de reglas simples o complejas y, a través de una disposición y ordenamiento de objetos y de imágenes en el espacio, los

El lector interesado en ver más imágenes del proyecto puede visitar el sitio https://www.miguelledezma.com/ para conocer más detalles de esta pieza y de otras obras que integran el proyecto Casa/escultura. 
ARTí́CULo

MIGUEL ÁNGEL LEDEZMA CAMPOS Dispositivos lúdicos para el arte artistas y los espectadores acceden a la experiencia del arte jugando y experimentado sensaciones de libertad y de placer, entre otras, las cuales son características de todo juego. Desde este enfoque, la obra de arte deviene en juguete y el espectador en usuario o jugador. El análisis del arte a través de las diversas tipologías del juego en el arte, permite no sólo comprender las obras artísticas desde un enfoque teórico y crítico, sino que también posibilita la producción artística, como es el caso de la obra Fraccionamiento Flamingos. I

\section{REFERENCIAS}

Artigas, G. (2013). Gustavo artigas 2000/2012. Proyecto editorial de arte contemporáneo basado en algunas obras producidas durante un lapso de doce años. Ciudad de México: 17, Instituto de Estudios Críticos.

Caillois, R. (1986). Los juegos y los hombres. La máscara y el vértigo. Ciudad de México: Fondo de Cultura Económica.

Cortés, J. M. (2010). La ciudad cautiva. Control y vigilancia del espacio urbano. Madrid: Akal. Deleuze, G. (1987). Foucault. Barcelona: Paidós.

Duvignaud, J. (1982). El juego del juego. Ciudad de México: Fondo de Cultura Económica.

Foucault, M. (2002). Vigilar y castigar. Buenos Aires: Siglo XXI.

Gadamer, H.-G. (1991). La actualidad de lo bello. El arte como juego, símbolo y fiesta. Barcelona: Paidós.

Gadamer, H.-G. (1997). Verdad y Método I. Salamanca: Sígueme.

Hard, M. y. (2000). Imperio. Massachussets: Harvard University Press.

Huizinga, J. (2000). Homo ludens. Madrid: Alianza.

Krauss, R. (2006). “La escultura en el campo expandido”. En H. Foster La posmodernidad. Barcelona: Kayros.

Lafferty, M. (2005). "La escala aberrante y el dilema de Eurípides”. En A. C. Danto Estética después del fin del arte. Ensayos sobre Arthur Danto. Madrid: La balsa de Medusa.

Ledezma-Campos, M. A. (2019). Juego y arte contemporáneo. El arte como competencia, azar, simulacro y vértigo. Pachuca de Soto: Universidad Autónoma del Estado de Hidalgo.

Rancière, J. (2010). El espectador emancipado. Buenos Aires: Bordes. 